\title{
Editorial PIAM October 2020
}

\section{Eujin Pei ${ }^{1}$}

Accepted: 27 October 2020 / Published online: 9 November 2020

(c) Springer Nature Switzerland AG 2020

Welcome to our Autumn issue of the journal, in which we will be looking at several topics concerning the powder bed fusion process, such as monitoring and detection of melt pool and spatter regions of Inconel 625, the effect of heat treatment on AlSi10Mg components, gold plating of AlSi10Mg parts, and the process gas influence on the microstructure and mechanical behavior of Inconel 718, etc. This issue includes a comprehensive review of metrology in additive manufacturing and other topics. Powder bed fusion is no doubt one of the most common and popular Additive Manufacturing processes used by the industry today. Research is currently focused on new powder development, extending the current build envelope, increasing production rate, non-destructive testing and compliance of parts as well as identifying new applications beyond aerospace, medical and the oil and gas industry.

As the world around us has been affected by COVID, this has forced institutions such as universities and training centres to think out of the box and to offer new approaches towards blended or mixed learning. It will perhaps make organisations think about adapting and fast-tracking the use of digital training methods such as online learning and the use of virtual reality. The long-term challenge is to ensure that students and learners continue to remain engaged and motivated through self-study and distance learning. If you would like to share your experiences through case studies or from industry knowledge transfer projects, do consider contributing an article to our journal. Within Europe, the Sector Skills Strategy in Additive Manufacturing (SAM) programme (https://www.skills4am.eu) started since January 2019 will run across 4 years. This programme is funded through the European Commission Erasmus + scheme that will develop an International Additive Manufacturing Qualification System (IAMQS), and promote the attractiveness of working in the Additive Manufacturing sector. This would be a timely opportunity for those of us who would like to upgrade our skills and gain a recognized qualification in this fast-growing sector.

For now, stay safe, take care, and enjoy reading this issue.

Eujin Pei

Progress in Additive Manufacturing Journal

October 2020

Publisher's Note Springer Nature remains neutral with regard to jurisdictional claims in published maps and institutional affiliations.
Eujin Pei

Eujinpei1@gmail.com

1 Brunel University London, London, UK 